Pacific Journal of Mathematics

CONCERNING DENIABILITY 


\title{
CONCERNING DENTABILITY
}

\author{
Michael Edelstein
}

It is shown that $c_{0}$ contains a closed and bounded convex body which is dentable but fails to have extreme points. On the other hand, there exists a strictly convex, closed, symmetric, convex body which fails to be dentable. (Thus dentability is, in general, unrelated to extremal structure.)

1. In [2], Rieffel introduced the notion of dentability for a subset $K$ of a Banach space $X$. Rephrased, it reads:

1.1. $K$ is dentable if, for every $\varepsilon>0$, there is an $x \in K$ and an $f \in X^{*}$ such that some hyperplane determined by $f$ separates $x$ from $K_{\varepsilon}=K \sim \overline{B(x, \varepsilon)}$, where $B(x, \varepsilon)$ is the ball of radius $\varepsilon$ about $x$.

One of the questions asked by Rieffel [Ibid., p. 77] is whether a closed and bounded convex set exists in some Banach space which is dentable but has no strongly exposed points. We answer this question by exhibiting a dentable symmetric closed convex body in $c_{0}$ which has no extreme points at all. To further show that the connection between dentability and extreme structure can be quite tenuous, we also exhibit in $c_{0}$ a strictly convex body which (in spite of the fact that each boundary part is exposed) is not dentable.

Another question of Rieffel, namely, whether each weakly compact subset of a Banach space is dentable has recently been answered in the affirmative by Troyanski [3]. The example of the unit ball in the conjugate Banach space $m$ is used by us (Proposition 3) to show that, in contrast to the above, a weak*-compact set need not be dentable.

2. Dentability properties of certain subsets of $c_{0}$ and $m$.

Proposition 1. There is a dentable closed and bounded convex body in $c_{0}$ which has no extreme point.

Proof. For $n=1,2, \cdots$ set $B_{n}=B\left(\left(2-2^{1-n}\right) e_{n}, 2^{1-n}\right)$, where $e_{n}=$ $\left\{x_{i}\right\} \in c_{0}$ with $x_{n}=1, x_{i}=0$ for $i \neq n$. Let $C_{n}=\left(-B_{n}\right) \cup B_{n}$ and $C=\overline{c o}\left(\bigcup_{n=1}^{\infty} C_{n}\right)$. We claim that $C$ has the desired properties.

(i) $C$ has no extreme points.

Suppose, for a contradiction, that $C$ has an extreme point

$$
y=\left(y_{1}, y_{2}, \cdots\right) \text {. }
$$


Clearly, $\|y\|>1$ (since $\bar{C}_{1}$ contains the unit ball) and without restriction of generality we may assume that $\|y\|=y_{k}$ for some $k$. Let $\left\{u^{(m)}\right\}$ be a sequence in $c o\left\{\bigcup_{n=1}^{\infty} C_{n}\right\}$ converging to $y$ with

$$
\left\|u^{(m)}-y\right\|<\min \left(y_{k}-1,2^{-k-2}\right) \quad(m=1,2, \cdots) .
$$

Write

$$
u^{(m)}=\sum_{i=1}^{l} \lambda_{i} u^{(m i)}
$$

with $u^{(m i)} \in C_{i}, \lambda_{i} \geqq 0(i=1,2, \cdots, l)$, and $\sum_{i=1}^{l} \lambda_{i}=1$. It is clear from the definition of the $B_{i}$ that, for $i>k$, $u_{k}^{(m i)} \leqq 2^{1-i} \leqq 2^{-k}$, where $u_{k}^{(m i)}$ is the $k$ th coordinate of $u^{(m i)}$.

Thus, by (1),

$$
1<u_{k}^{(m)}=\sum_{i=1}^{k} \lambda_{i} u_{k}^{(m i)}+\sum_{i=k+1}^{l} \lambda_{i} u_{k}^{(m i)} \leqq 2 \sum_{i=1}^{i=k} \lambda_{i}+2^{-k}\left(1-\sum_{i=1}^{k} \lambda_{i}\right) .
$$

It follows that

$$
\sum_{i=1}^{k} \lambda_{i}>\frac{1-2^{-k}}{2-2^{-k}}>\frac{1}{2}-\frac{1}{2^{k+1}} \geqq \frac{1}{4} .
$$

Now let $j$ be a positive integer with the property that $\left|y_{j}\right|<2^{-k-3}$. To show that $y$, contrary to assumption, cannot be an extreme point, we exhibit two points $\bar{y}$ and $\underline{y}$ in $C$ such that $\bar{y}_{j}>\underline{y}_{j}>y_{-j}$ with all other coordinates of these points equal. To this end define $\left\{\bar{u}^{(m)}\right\}$ and $\left\{\underline{u}^{(m)}\right\}$ as follows.

Using (2), set

$$
\bar{u}_{n}^{(m i)}=\underline{u}_{n}^{(m i)}=u_{n}^{(m i)}
$$

for $m=1,2, \cdots, j ; n \neq j, i=1,2, \cdots, l$;

$$
\bar{u}_{j}^{(m i)}=-\underline{u}_{j}^{(m i)}=\left\{\begin{array}{ll}
2^{-k} & \text { for } i \leqq k \\
0 & \text { for } i>k
\end{array} .\right.
$$

It follows from (3) that

$$
\bar{u}_{j}^{(m)}=-\underline{u}_{j}^{(m)} \geqq 2^{-k-2} .
$$

Thus, $\bar{u}_{j}^{(m)} \geqq y_{j}+2^{-k-3}$ and $\underline{u}_{j}^{(m)} \leqq y_{j}-2^{-k-3}$. It is now obvious that $\left\{\bar{u}^{(m)}\right\}$ and $\left\{\underline{u}^{(m)}\right\}$ converge to points $\bar{y}$ and $\underline{y}$, respectively, having the desired properties. This completes the proof that $C$ has no extreme points.

(ii) $C$ is dentable.

Let $\varepsilon>0$ be given and choose $n$ so that $2^{2-n}<\varepsilon$. We show that $\overline{c o}(C \sim B)$ wehre $B=B\left(2 e_{n}, \varepsilon\right)$ does not contain $2 e_{n} \in C$. 
To this end, consider the set $H^{(n)}=\left\{x \in \operatorname{co}\left(\bigcup_{n=1}^{\infty} C_{n}\right): x_{n} \geqq 2-2^{-n}\right\}$. Any member $h$ of $H^{(n)}$ can be represented in the form $h=\sum_{i=1}^{m} \lambda_{i} x^{i}$ with $\lambda_{i} \geqq 0, \sum_{i=1}^{m} \lambda_{i}=1$ and $x_{i} \in C_{i}, i=1,2, \cdots, m ; m \geqq n$. Now, by definition, $h_{n}=\sum_{i=1}^{m} \lambda_{i} x_{n}^{i} \geqq 2-2^{-n}$. On the other hand,

$$
\begin{aligned}
h_{n} & =\lambda_{n} x_{n}^{n}+\sum_{i \neq m} \lambda_{i} x_{n}^{i} \leqq \lambda_{n} x_{n}^{n}+\left(1-\lambda_{n}\right) \\
& =\lambda_{n}\left(x_{n}^{n}-1\right)+1 \leqq \lambda_{n}+1 .
\end{aligned}
$$

It follows that $\lambda_{n} \geqq 1-2^{-n}$. Consequently,

$$
\left\|2 e_{n}-h\right\| \leqq 2^{2-n} \quad\left(h \in H^{(n)}\right),
$$

for $\left|\left(2 e_{n}\right)_{n}-h_{n}\right| \leqq\left|2-\left(2-2^{-n}\right)\right|=2^{-n}$ and, for $k \neq n$,

$$
\left(2 e_{n}-h\right)_{k}=\left|\sum \lambda_{i} x_{k}^{i}\right| \leqq 1-\lambda_{n} \leqq 2^{2-n} .
$$

Thus $B\left(2 e_{n}, \varepsilon\right)$ contains $H^{(n)}$ and clearly, $\overline{C \sim H^{(n)}}$ is convex with $2 e_{n} \notin \overline{C \sim H^{(n)}}$. We have shown that $C$ is dentable completing thereby the proof of the proposition.

Proposition 2. In $c_{0}$ there exists a symmetric, closed and bounded convex body which is strictly convex and fails to be dentable.

Proof. Let

$$
C=\left\{x \in c_{0}:\|x\|+\left(\sum_{n-1}^{\infty} 2^{-n} x_{n}^{2}\right)^{1 / 2} \leqq 1\right\} .
$$

It is well-known (cf. [1, p. 362]) that $C$ defines an equivalent strictly convex norm and, therefore, only the nondentability has to be shown. We note that for $x=\left(x_{1}, x_{2}, \cdots, x_{n}, \cdots\right) \in \operatorname{bdry} C$, we have $\|x\| \geqq 1 / 2$ so that for such an $x$ there is an integer $m$ with $\left|x_{m}\right|=\|x\| \geqq 1 / 2$. Let $1 / 4>\varepsilon>0$ and choose $0<\delta<\varepsilon / 2$ small enough so that $\|x\|=$ $\left\|x^{\prime}\right\|+\delta$ if $x^{\prime}$ is the vector obtained from $x$ by replacing each coordinate $x_{i}$, with $\left|x_{i}\right|=\|x\|$, by $\left|x_{i}\right|-\delta$. Next, let $k$ be large enough so that $\left|x_{k}\right|<\delta$ and

$$
\left(\sum_{n \neq k} 2^{-n} x_{n}^{2}+\frac{1}{2^{k+4}}\right)^{1 / 2} \leqq\left(\sum_{n=1}^{\infty} 2^{-n} x_{n}^{2}\right)^{1 / 2}+\delta
$$

To prove nondentability, it clearly suffices to exhibit $u, v \in C$ such that $\|(u+v) / 2-x\|<\delta$ and $\|u-v\| \geqq 1 / 2$. To this end, set $u_{i}=$ $v_{i}=x_{i}$ for those $i \neq k$ for which $\left|x_{i}\right|<\|x\| ; u_{k}=-v_{k}=1 / 4$; and $u_{j}=v_{j}=x_{j}-\delta x_{j} /\left|x_{j}\right|$, otherwise. Since $\|u\|=\|v\|=\|x\|-\delta$ and

$$
\left(\sum_{n=1}^{\infty} 2^{-n} u_{n}^{2}\right)^{1 / 2}=\left(\sum_{n=1}^{\infty} 2^{-n} v_{n}^{2}\right)^{1 / 2} \leqq\left(\sum_{n=1}^{\infty} 2^{-n} x_{n}^{2}\right)^{1 / 2}+\delta,
$$


we have $u, v \in C$. Also, $\|(u+v) / 2-x\|<\delta$, since $\left|((u+v) / 2-x)_{k}\right|=$ $\left|x_{k}\right|<\delta$, and, for all coordinates $j \neq k$ at which $u, v$ and $x$ are distinct, we have $\left|((u+v) / 2-x)_{j}\right|=\delta$. Finally,

$$
\|u-v\|=\left\|u_{k}-v_{k}\right\|=\frac{1}{2} .
$$

Proposition 3. The unit ball in $m$ is not dentable.

Proof. Let $0<\varepsilon<1 / 4$ and $x=\left(x_{1}, x_{2}, \cdots\right) \in m$ with $\|x\| \leqq 1$. Either (i) there is an integer $k$ with $\left|x_{k}\right| \leqq 1 / 4$, or (ii) for every index $j,\left|x_{j}\right|>1 / 4$.

In case (i), define $\bar{x}$ and $\underline{x}$ by setting

$$
\begin{aligned}
& \bar{x}=\left(x_{1}, x_{2}, \cdots, x_{k}+\frac{1}{4}, \cdots\right) \\
& \underline{x}=\left(x_{1}, x_{2}, \cdots, x_{k}-\frac{1}{4}, \cdots\right)
\end{aligned}
$$

so that $(1 / 2)(\bar{x}+\underline{x})=x$ and $\|\bar{x}-\underline{x}\|=1 / 2>\varepsilon$.

In case (ii), define

$$
x^{(i)}=\left(x_{1}, x_{2}, \cdots, x_{i}-\frac{x_{i}}{4\left|x_{i}\right|}, \cdots\right) \quad(i=1,2, \cdots),
$$

so that $\left\|x-x^{(i)}\right\|=1 / 4$.

Now, $x \in \overline{c o}\left\{x^{(i)}: i=1,2, \cdots\right\}$. For,

$$
\left(x-\frac{1}{j} \sum_{n=1}^{j} x^{(n)}\right)_{k}=\left\{\begin{array}{l}
0, \quad \text { if } k>j \\
\frac{1}{j}\left(x_{k}-\frac{x_{k}}{4\left|x_{k}\right|}\right)
\end{array}\right.
$$

showing that $(1 / j) \sum_{n=1}^{j} x^{(n)} \rightarrow x$. Thus, the dentability condition fails, proving the proposition.

\section{REFERENCES}

1. G. Köthe, Topological Vector Spaces I, Berlin-Heidelberg-New York, 1969.

2. M. A. Rieffel, Dentable subsets of Banach spaces with application to a RadonNikodym theorem, Proc. Conf. Functional Anal., Thompson Book Co., Washington, 1967 pp. 71-77.

3. S. L. Troyanski, On locally uniformly convex and differentiable norms in certain non-separable Banach spaces, Studia Math., 37 (1971), 173-179.

Received January 27, 1972. This research was supported by the National Research Council of Canada, Grant A-3999. The author is a visiting scholar at the University of California, Berkeley; on sabbatical leave from Dalhousie University. 


\section{PACIFIC JOURNAL OF MATHEMATICS}

\section{EDITORS}

D. Gilbarg and J. Milgram Stanford University

Stanford, California 94305

R. A. Beaumont

University of Washington

Seattle, Washington 98105
J. DugundJI

Department of Mathematics

University of Southern California

Los Angeles, California 90007

RICHARD ARENS

University of California

Los Angeles, California 90024

ASSOCIATE EDITORS
E. F. BECKENBACH
B. H. NeumanN
F. WOLF
K. YoSHIDA

\section{SUPPORTING INSTITUTIONS}

UNIVERSITY OF BRITISH COLUMBIA

CALIFORNIA INSTITUTE OF TECHNOLOGY

UNIVERSITY OF CALIFORNIA

MONTANA STATE UNIVERSITY

UNIVERSITY OF NEVADA

NEW MEXICO STATE UNIVERSITY

OREGON STATE UNIVERSITY

UNIVERSITY OF OREGON

OSAKA UNIVERSITY
UNIVERSITY OF SOUTHERN CALIFORNIA

STANFORD UNIVERSITY

UNIVERSITY OF TOKYO

UNIVERSITY OF UTAH

WASHINGTON STATE UNIVERSITY

UNIVERSITY OF WASHINGTON

$\stackrel{*}{*} \stackrel{*}{*} \stackrel{*}{*}$ AMERICAN MATHEMATICAL SOCIETY

NAVAL WEAPONS CENTER 


\section{Pacific Journal of Mathematics}

\section{Vol. 46, No. $1 \quad$ November, 1973}

Allan Francis Abrahamse, Uniform integrability of derivatives on $\sigma$-lattices .......................................... 1

Ronald Alter and K. K. Kubota, The diophantine equation $x^{2}+D=p^{n} \ldots \ldots \quad 11$

Grahame Bennett, Some inclusion theorems for sequence spaces .......... 17

William Cutler, On extending isotopies ........................ 31

Robert Jay Daverman, Factored codimension one cells in Euclidean

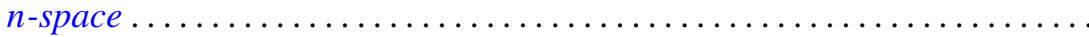

Patrick Barry Eberlein and Barrett O’Neill, Visibility manifolds ............ 45

M. Edelstein, Concerning dentability .......................... 111

Edward Graham Evans, Jr., Krull-Schmidt and cancellation over local

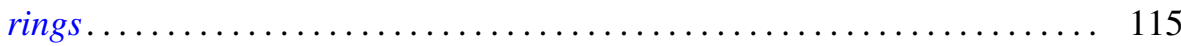

C. D. Feustel, A generalization of Kneser's conjecture ................ 123

Avner Friedman, Uniqueness for the Cauchy problem for degenerate parabolic equations .......................................... 131

David Golber, The cohomological description of a torus action ............ 149

Alain Goullet de Rugy, Un théorème du genre "Andô-Edwards" pour les

Fréchet ordonnés normaux..............................

Louise Hay, The class of recursively enumerable subsets of a recursively enumerable set ........................................

John Paul Helm, Albert Ronald da Silva Meyer and Paul Ruel Young, On orders of translations and enumerations...

Julien O. Hennefeld, A decomposition for $B(X)^{*}$ and unique Hahn-Banach

extensions

Gordon G. Johnson, Moment sequences in Hilbert space .

Thomas Rollin Kramer, A note on countably subparacompact spaces ...

Yves A. Lequain, Differential simplicity and extensions of a derivation ....

Peter Lorimer, A property of the groups Aut $\mathrm{PU}\left(3, q^{2}\right) \ldots$

225

Yasou Matsugu, The Levi problem for a product manifold.

231

John M.F. O'Connell, Real parts of uniform algebras ......

William Lindall Paschke, A factorable Banach algebra without bounded

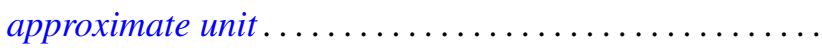

Ronald Joel Rudman, On the fundamental unit of a purely cubic field ....

Tsuan Wu Ting, Torsional rigidities in the elastic-plastic torsion of simply connected cylindrical bars .........................

Philip C. Tonne, Matrix representations for linear transformations on analytic sequences...................................

Jung-Hsien Tsai, On E-compact spaces and generalizations of perfect

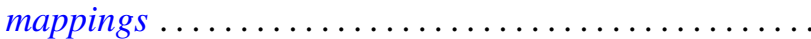

Alfons Van Daele, The upper envelope of invariant functionals majorized by an invariant weight. .. 